\title{
Модовая декомпозиция лазерного излучения, распространяющегося в многомодовом волокне в режиме керровской самочистки
}

\author{
М.Д. Гервазиев $^{1,2, *}$, Д.С. Харенко ${ }^{1,2}$, И. Жданов ${ }^{1,2}$, В.А. Гонта ${ }^{1,2}$, \\ Е.В. Подивилов ${ }^{1,2}$, С.А. Бабин ${ }^{1,2}$, С. Вабниц ${ }^{1,3}$ \\ ${ }^{1}$ Новосибирский государственный университет \\ ${ }^{2}$ Институт автоматики и электрометрии СО РАН \\ ${ }^{3}$ DIET, Sapienza University of Rome, Italy \\ *E-mail: gervaziev.m@gmail.com
}

DOI: $10.31868 /$ RFL2020.106-108

Многомодовые волокна долгое время оставались невостребованными из-за плохого качества пучка, которое обратно пропорционально количеству возбуждённых мод. Однако интенсивное исследование нелинейных эффектов при распространении мощного лазерного излучения в многомодовых волокнах с градиентным профилем показателя преломления привело к открытию ряда неожиданных явлений, таких как керровская самочистка пучка [1] и генерация суперконтинуума с импульсами высокой пиковой мощности [2]. Механизм самочистки заключается в том, что большая часть энергии пучка перетекает в фундаментальную моду с сопутствующим перераспределением энергии в сторону мод высокого порядка. Увеличение энергии фундаментальной моды приводит к увеличению качества пучка. Стандартным способом определения качества пучка является измерение параметра $\mathrm{M}^{2}$ (м-квадрат). То есть фактически определяется степень отклонения расходимости пучка от гауссового. Но поскольку самочистка представляет из себя нелинейное перераспределение энергии, переносимой большим числом мод волокна, такой подход не вполне корректен, и гораздо более информативным методом представляется модовая декомпозиция выходного луча.

Модовая декомпозиция - это метод анализа излучения, заключающийся в измерении амплитуд и относительных фаз мод, входящих в состав пучка. Существующие методы декомпозиции основаны на генетических алгоритмах [3], адаптивной оптике [4] или фазовой модуляции [5]. Реализовать последний вариант возможно при помощи пространственного модулятора света (SLM, от англ. - spatial light modulator). SLM - это прибор, обычно управляемый с помощью компьютера, который накладывает определенную форму пространственной модуляции (амплитудной, фазовой или амплитудно-фазовой) на излучение. Существующие работы по модовой декомпозиции включали в себя анализ пучка на выходе из маломодовых волокон, наша задача заключалась в том, чтобы сделать метод пригодным для использования в случае волокон с большим числом мод и градиентным профилем показателя преломления.

Принципиальная схема эксперимента приведена на рисунке 1. Используя свойство ортонормированности волоконных мод, разложение Якоби-Ангера и теоремы о преобразовании Фурье, фазовые маски формируются таким образом, чтобы центр первого порядка дифракции содержал информацию об амплитуде моды или её относительной фазе (относительно некоторой моды, обычно фундаментальной) [5]. В работе проведено численное моделирование процесса декомпозиции для случайно сгенерированного пучка. Показано, что амплитуды и фазы восстанавливаются с точностью до $10^{-7}$, а восстановленный пучок практически неотличим от исходного. Добавлена дискретизация с целью 
численно сравнить результаты для 10-битного и 8-битного модуляторов, Вычисления показали, что разница в дискретизации существенно не сказалась на точности определения амплитуд $\left(\sim 10^{-4}\right)$. В случае определения фаз разница более существенна, но все равно не критична (точность $10^{-3}$ для 10 бит, и $10^{-2}$ для 8 бит).

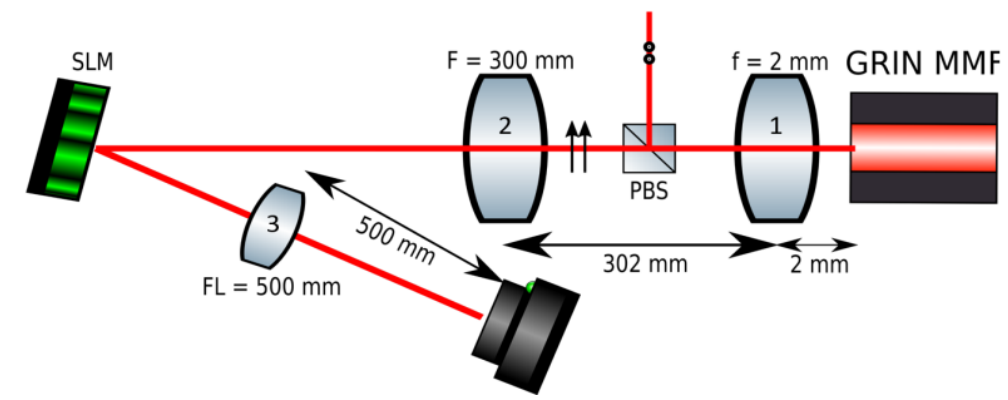

Рис. 1. Схема эксперимента по декомпозиции пучка. Линзы 1 и 2 переносят распределение поля в ближней зоне (с торца волокна) на модулятор. Линза 3 выполняет преобразование Фурье от промодулированного поля (формирует распределение поля в дальней зоне).

Проверено влияние разрешения фазовой маски на результаты декомпозиции. Сравнивались маски с размером фундаментальной моды 120,90 , 60 и 30 пикселей. Обнаружено, что с уменьшением разрешения особенно сильное увеличение погрешности происходит при значении радиуса моды в 30 пикселей (рис.2 $(\mathrm{a}, б))$. При этом форма восстановленного пучка от исходного отличается незначительно (рис.2(в)).
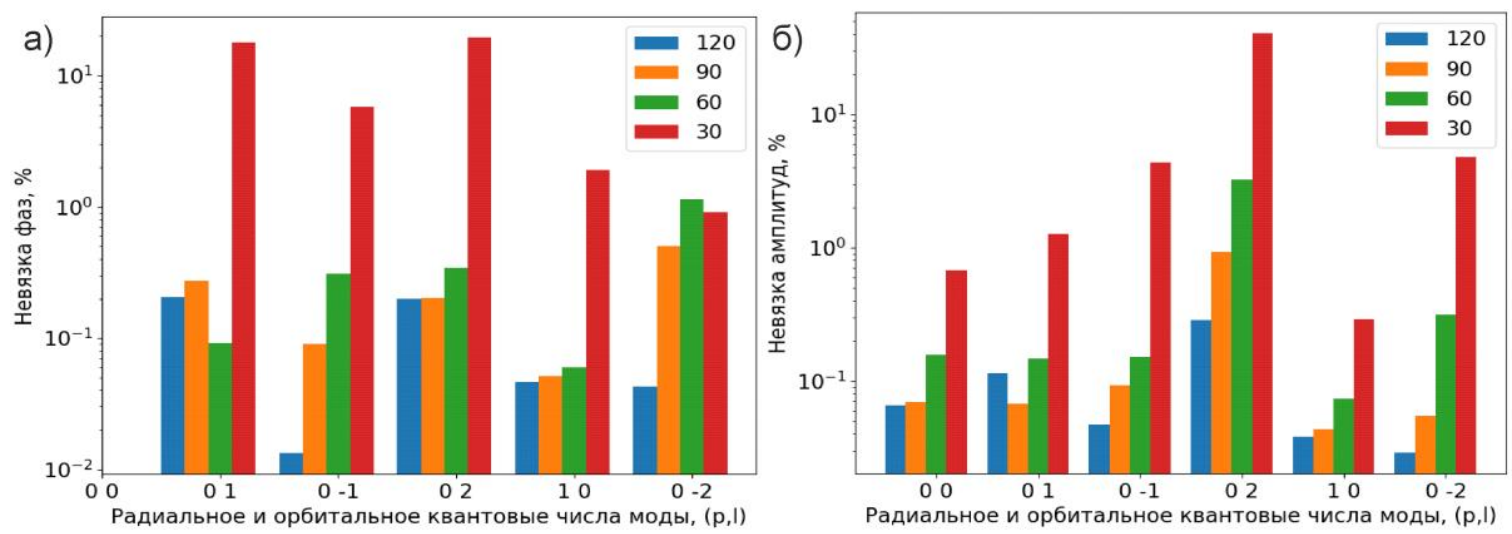

B)
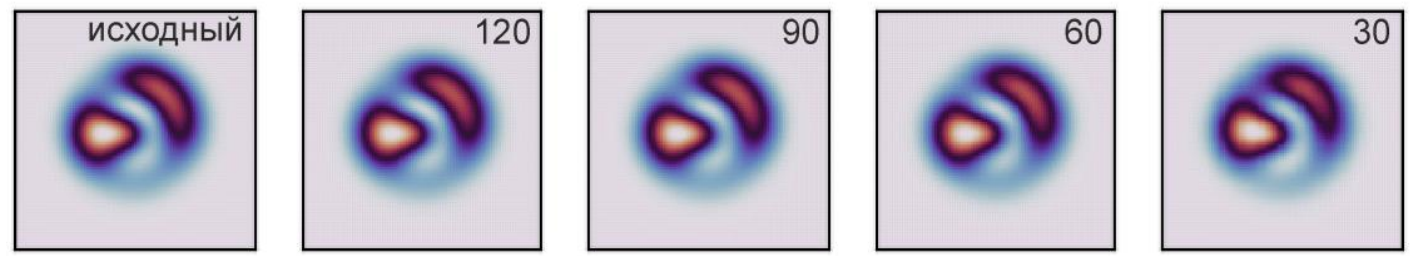

Рис. 2. а) невязка фаз (логарифмическая шкала), рассчитанных в процессе моделирования декомпозиции; б) невязка амплитуд (логарифмическая шкала), рассчитанных в процессе моделирования декомпозиции; в) слева направо - оригинальный пучок; пучок, восстановленный в результате декомпозиции с размером фундаментальной моды 120 пикселей; 90 пикселей; 60 пикселей; 30 пикселей;

Работа поддержана Министерством науки и высшего образования Российской Федерации (14.Y26.31.0017). 


\section{Литература}

[1] K. Krupa, A. Tonello, et al. Nat. Photonics 11, 237-241 (2017)

[2] G. Lopez-Galmiche, Z. S. Eznaveh, et al. Opt. Lett. 41, 2553 (2016)

[3] L. Li, J. Leng, et al. Opt. Express 25, 19680 (2017)

[4] C. Schulze, D. Naidoo, et al. Opt. Express 20, 19714 (2012)

[5] D. Flamm, D. Naidoo, et al. Opt. Letters 37, 2478 (2012) 